\title{
BIAYA KEMACETAN PADA KENDARAAN PRIBADI DI PURWOKERTO
}

\section{CONGESTION COSTS ON PRIVATE VEHICLES IN PURWOKERTO}

\author{
Juanita \\ Program Studi S1 Teknik Sipil, Fakultas Teknik dan Sains \\ Universitas Muhammadiyah Purwokerto
}

Informasi Artikel
Dikirim,
Direvisi,
Diterima,

Korespondensi Penulis:

Juanita

Program Studi Teknik Sipil Universitas Muhammadiyah Purwokerto

JL. K.H. Ahmad Dahlan Purwokerto, 53182

Email:

juanitamstr@gmail.com

\begin{abstract}
ABSTRAK
Kemacetan di jalan raya akan mengakibatkan kerugian terkait pengeluaran bahan bakar, waktu tempuh dan lain lain. Biaya kerugian yang diakibatkan kemacetan dengan sepeda motor di J1 Raya Dukuhwaluh per trip sebesar Rp 119,5,- arah timur barat, dan arah barat timur Rp 65,-, sedangkan Jl. Kombas Suprapto Rp 112,6,- arah timur barat dan Rp 146,8,- arah barat timur. Biaya kerugian kemacetan dengan mobil di Jl Raya Dukuhwaluh per trip sebesar Rp 656.28,- arah timur barat, sedangkan arah barat timur Rp 929,73,-. Jl. Kombas Suprapto Rp 674,51,- arah timur barat dan Rp 710,97,- arah barat timur. Sedangkan dengan angkot biaya per trip Rp 4000,- Biaya kerugian akibat kemacetan pada kedua ruas jalan yaitu Jl Raya Dukuhwaluh dan Jl Kombas Suprapto dengan pemakaian kendaraan pribadi (sepeda motor dan mobil) lebih rendah dibandingkan penggunaan angkot dengan tarif flat.
\end{abstract}

Kata Kunci : Kemacetan, biaya, kendaraan pribadi.

\section{ABSTRACT}

Congestion on the road will result in loss of expenses, travel time and others. The cost of losses due to congestion on motorbikes on Jl Raya Dukuhwaluh per trip is IDR 119.50 east-west direction, and east-west direction IDR 65.00, while Jl. Kombas Suprapto IDR 112.60 - east-west direction and IDR 146.80 - west-east direction. The cost of congestion loss by car on Jl Raya Dukuhwaluh per trip is IDR 656.28, - east-west direction, while the west-east direction is IDR 929.73, -. Jl. Kombas Suprapto IDR 674.51, - east-west direction and IDR 710.97, - east-west direction. Meanwhile, the cost of public transportation costs IDR 4,000 per trip. The cost of congestion loss on the two roads, Jl Raya Dukuhwaluh and Jl Kombas Suprapto with the use of private vehicles (motorbikes and cars) is lower than the use of public transportation with flat rates.

Keyword : Congestion, costs, private vehicle 


\section{PENDAHULUAN}

Kota Purwokerto merupakan ibukota Kabupaten Banyumas yang terletak di bagian selatan Jawa Tengah. Wilayah administrasi Kota Purwokerto terdiri dari 4 Kecamatan yaitu Purwokerto Timur, Purwokerto Selatan, Purwokerto Barat, dan Purwokerto Utara. Luas wilayah administrasi per kecamatan yaitu Purwokerto Timur seluas 841.91 Ha, Purwokerto Barat seluas 739.73 Ha, Purwokerto Utara seluas 901.39 Ha, dan Purwokerto Selatan seluas 1.375.31 Ha. Kepadatan penduduk tertinggi ada di Purwokerto Barat sebesar 7.377 jiwa $/ \mathrm{km}^{2}$, sedangkan kepadatan penduduk Kembaran sebesar $3.184 \mathrm{jiwa} / \mathrm{km}^{2}$ [1].

Kepadatan penduduk dan penambahan penduduk luar kota sebagai mahasiswa ke Purwokerto akan menambah penggunaan kendaraan bermotor baik angkutan umum maupun kendaraan pribadi. Distribusi perjalanan dari rumah di Purwokerto untuk tujuan perjalanan bekerja sebesar 64,4\%, bisnis $28 \%$, ke kampus/ sekolah $11.3 \%$, ke pasar 6,7 \% dan lainnya 3,1\%. Moda yang dipergunakan sepeda motor sebesar 67\%, menggunakan mobil pribadi sebesar 23,7\%, menggunakan angkutan umum sebesar 6,2\%, menggunakan becak dan lainnya 1,5\% [2]. Penggunaan kendaraan pribadi yang lebih tinggi (sepeda motor dan mobil) dbandingkan angkutan umum akan mempengaruhi kemacetan di jalan. Kualitas layanan angkutan umum di Purwokerto masih kurang baik ditunjukan dengan nilai CSI (customer satisfaction index) $57 \%$ dan nilai gap antara kinerja dengan harapan penumpang bernilai negatif. Frekuensi penggunaan angkot didominasi $70 \%$ kadang-kadang menggunakan angkot dengan alasan kendaraan dipakai yang lain atau sedang rusak $48 \%$, tidak mempunyai kendaraan 23\% dan lebih mudah menggunakan angkot hanya 19\% [3]. Banyaknya jumlah penggunaan kendaraan pribadi di jalan tersebut perlu kajian pada biaya kerugian akibat kemacetan. karena sebagian besar lebih menggunakan kendaraan pribadi daripada angkutan umum. Tujuan penelitian ini dilakukan untuk mengetahui nilai kerugian akibat kemacetan lalu lintas pada kendaraan pribadi khususnya sepeda motor dan mobil, sehingga diketahui besaran biaya kerugian tersebut dibandingkan penggunaan angkutan umum.

\section{TINJAUAN LITERATUR}

Terdapat hubungan antara tiga karakteristik primer dalam teori arus lalu lintas yang saling terkait yaitu volume, kecepatan dan kepadatan. Meningkatnya lalu lintas kendaraan mengakibatkan biaya eksternal antara lain kemacetan, risiko kecelakaan, konsumsi energi, emisi polusi [4]. Kemacetan lalu lintas terjadi dalam ruang dan waktu berupa pola lalu lintas padat yang merambat dalam suatu jaringan lalu lintas [5].

Biaya kerugian akibat kemacetan digunakan rumus dari [6] :

$$
C=N x\left[G A+\left(1-\frac{A}{B}\right) V^{\prime}\right] T
$$

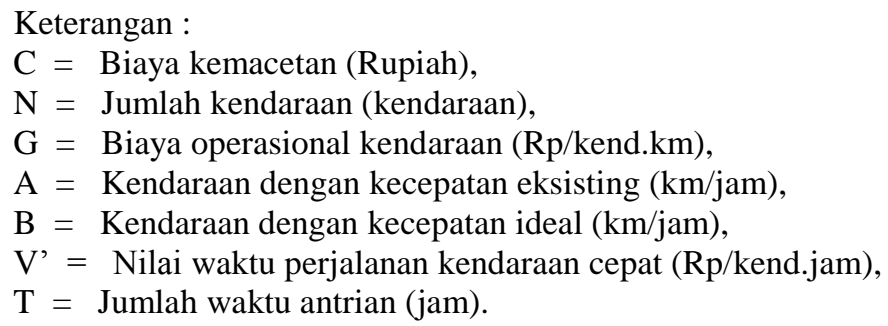

\section{METODE PENELITIAN}

Lokasi penelitian berada di Jl Raya Dukuhwaluh dan Jl. Kombes Suprapto. Jalan tersebut dipilih karena terdapat titik-titik kemacetan yang menyebabkan pengurangan kecepatan kendaraan sehingga berdampak pada biaya atau kerugian yang ditimbulkan akibat kemacetan. Data kecepatan kendaraan sepeda motor dan kendaraan ringan (mobil penumpang), harga-harga suku cadang dan bahan bakar. Biaya operasional kendaraan yang digunakan dalam penelitian ini untuk sepeda motor Honda Revo tahun 2012 sedangkan mobil digunakan Avanza tipe manual tahun 2012.

\section{HASIL DAN PEMBAHASAN}

\subsection{Kecepatan Lalu Lintas}

Kecepatan kendaraan dalam perhitungan dilakukan melalui survey langsung di kedua jalan sebelum ada pandemi covid-19. Kecepatan sepeda motor yang digunakan disini yaitu kecepatan sesaat di jalan Raya Dukuhwaluh dan jalan Kombas Suprapto arah barat - timur dan barat - timur. Kecepatan kendaraan motor dan mobil di jalan Raya Dukuhwaluh disajikan pada Gambar 1. Dan Gambar 2. 


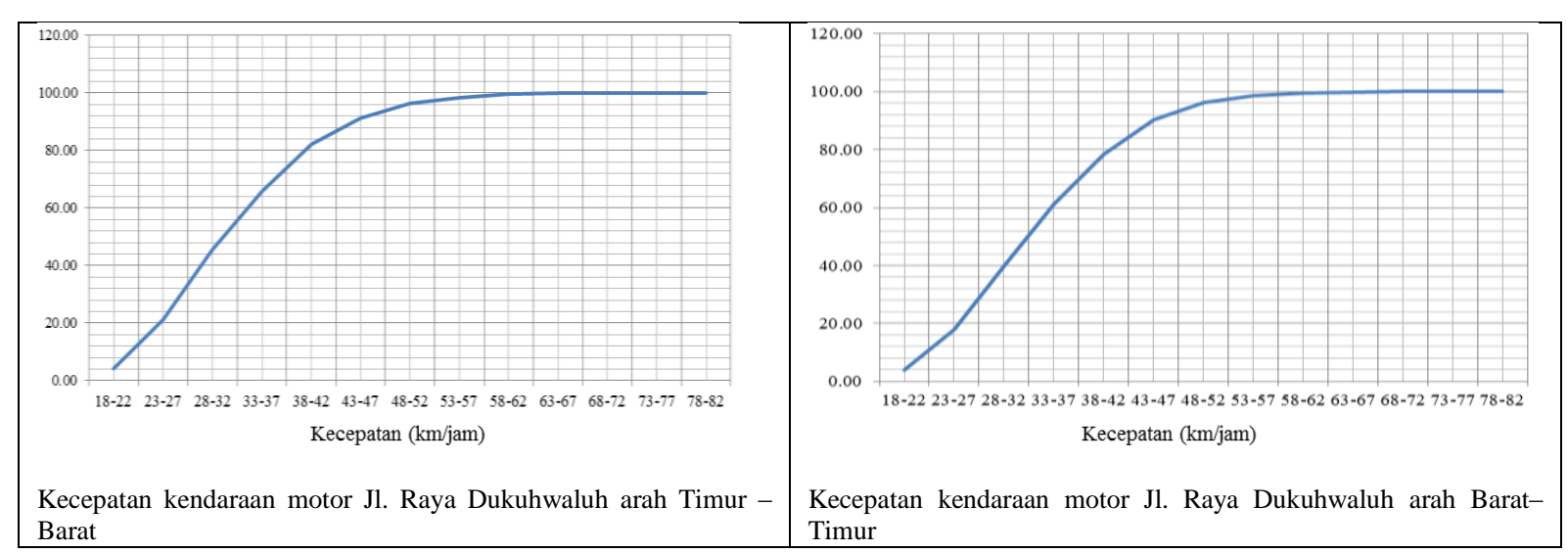
Barat

Gambar 1. Distribusi kumulatif kecepatan kendaraan motor Jl. Raya Dukuhwaluh kedua arah

Pada Gambar 1. kecepatan sepeda motor $85 \%$ kendaraan bergerak pada atau di bawah kecepatan 43,17 $\mathrm{km} / \mathrm{jam}$ dan $15 \%$ bergerak di atas kecepatan tersebut pada arah Barat - Timur. Sedangkan arah Timur - Barat kecepatan kendaraan $85 \%$ kendaraan bergerak pada atau di bawah kecepatan 38,63 km/jam.

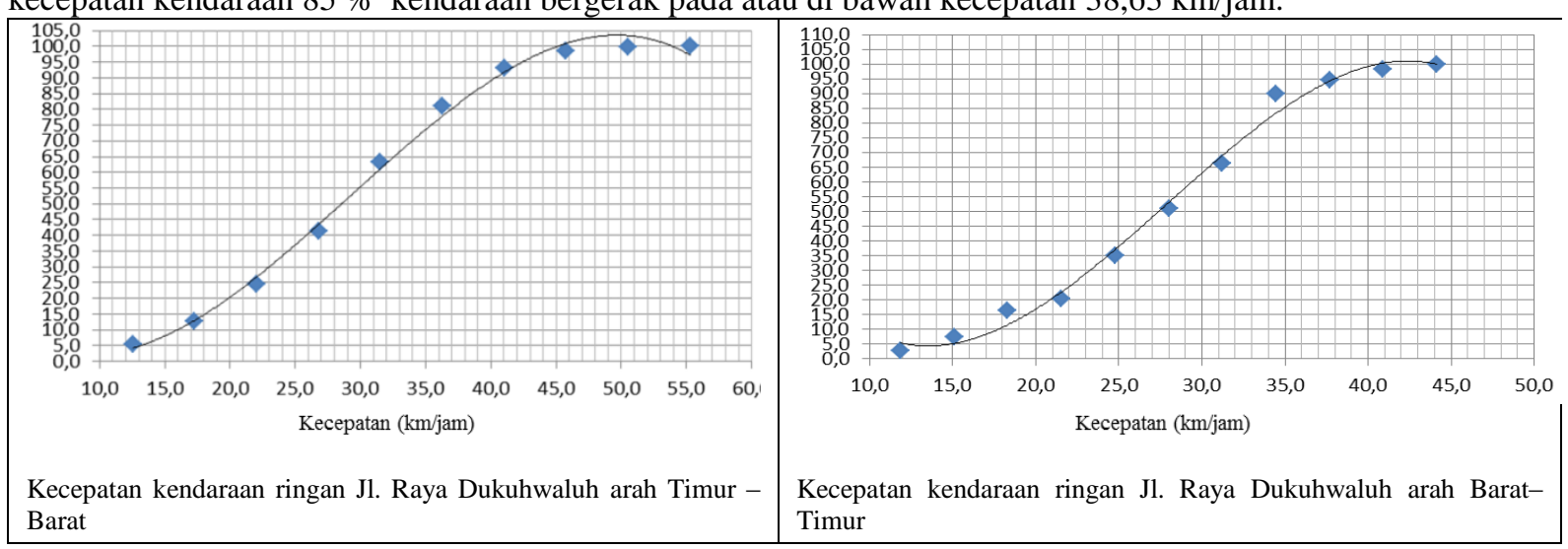
Barat

Gambar 2. Distribusi kumulatif kecepatan kendaraan ringan Jl. Raya Dukuhwaluh kedua arah

Pada Gambar 2. kecepatan kendaraan ringan (mobil pribadi) $85 \%$ kendaraan bergerak pada atau di bawah kecepatan $35 \mathrm{~km} / \mathrm{jam}$ dan $15 \%$ bergerak di atas kecepatan tersebut pada arah Barat - Timur. Sedangkan arah Timur - Barat kecepatan kendaraan $85 \%$ kendaraan bergerak pada atau di bawah kecepatan 38,5 km/jam.

Kecepatan kendaraan sepeda motor dan mobil di jalan Kombas Suprapto disajikan pada Gambar 3 dan Gambar 4.

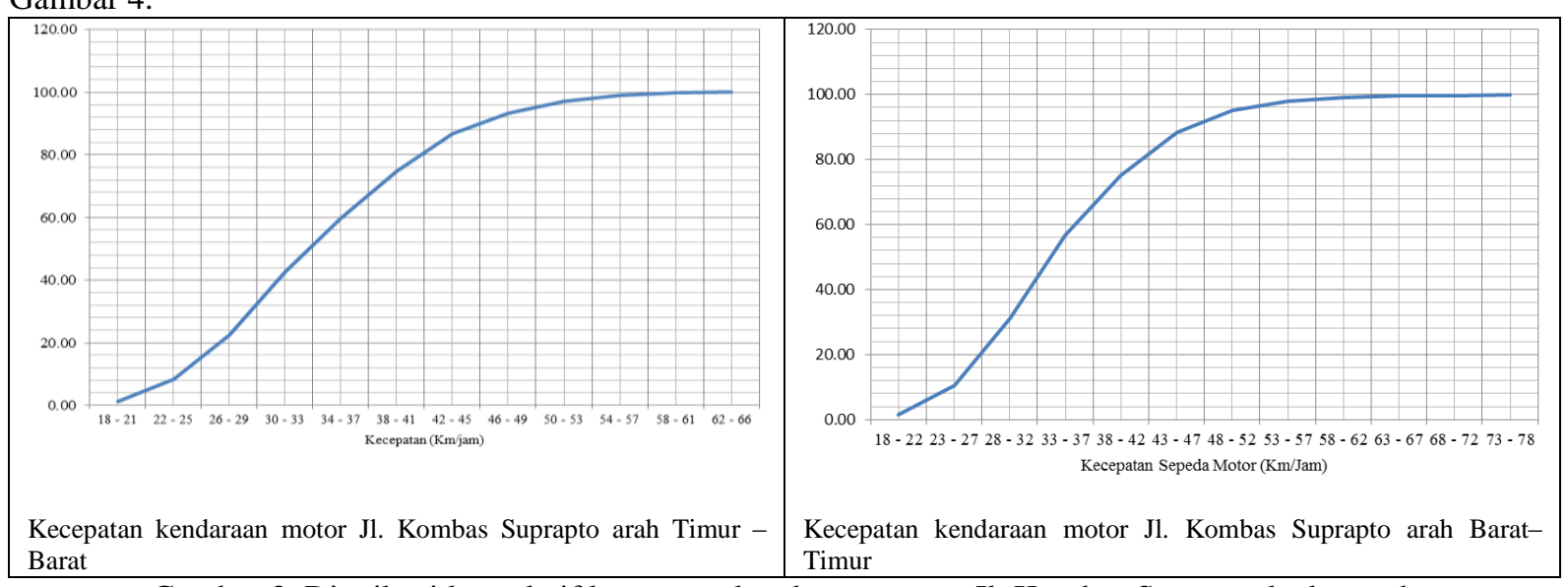

Gambar 3. Distribusi kumulatif kecepatan kendaraan motor Jl. Kombas Suprapto kedua arah

Pada Gambar 3. kecepatan sepeda motor $85 \%$ kendaraan bergerak pada atau di bawah kecepatan 38,17 $\mathrm{km} / \mathrm{jam}$ dan $15 \%$ bergerak di atas kecepatan tersebut pada arah Barat - Timur. Sedangkan arah Timur - Barat 
kecepatan kendaraan $85 \%$ kendaraan bergerak pada atau di bawah kecepatan 40,48 km/jam. Sedangkan kecepatan kendaraan ringan (mobil) pada jalan Kombas Suprapto untukkedua arah disajikan pada Gambar 4.

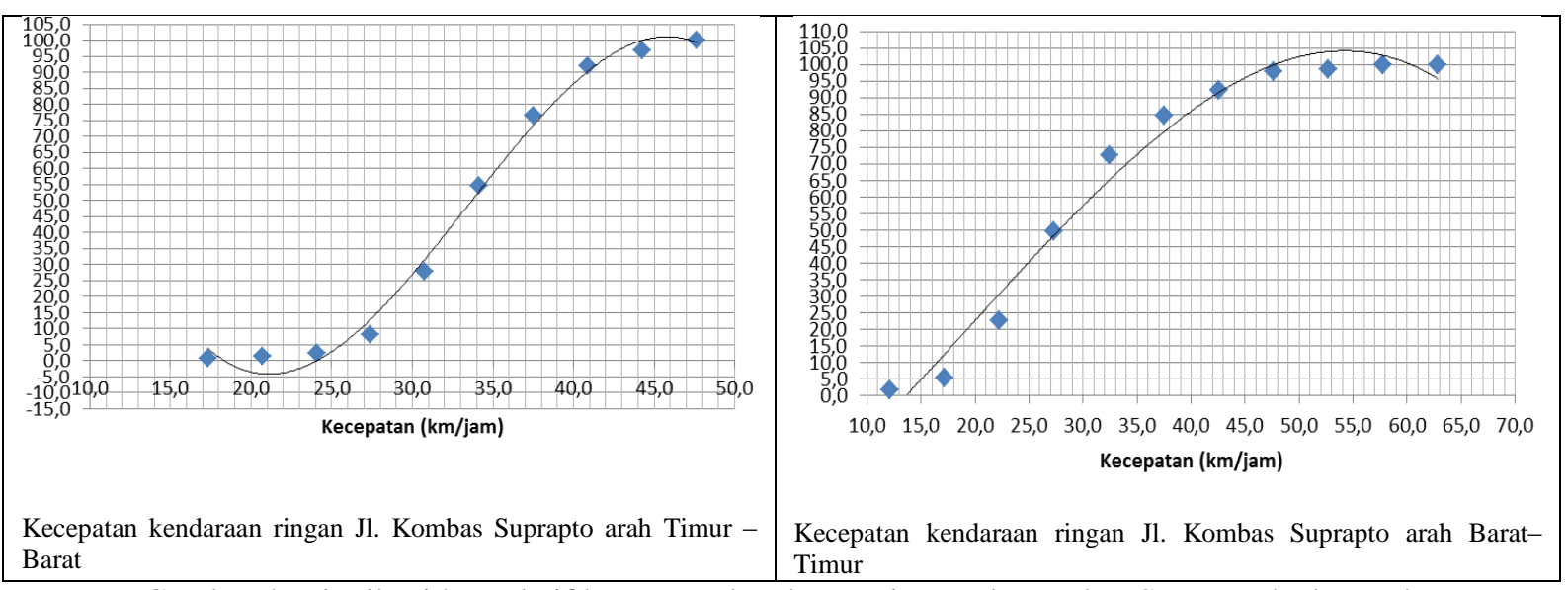

Gambar 4. Distribusi kumulatif kecepatan kendaraan ringan Jl. Kombas Suprapto kedua arah

Pada Gambar 4. kecepatan kendaraan ringan (mobil pribadi) $85 \%$ kendaraan bergerak pada atau di bawah kecepatan $39 \mathrm{~km} / \mathrm{jam}$ dan $15 \%$ bergerak di atas kecepatan tersebut pada arah Barat - Timur. Sedangkan arah Timur - Barat kecepatan kendaraan $85 \%$ kendaraan bergerak pada atau di bawah kecepatan 39,5 km/jam.

\subsection{Biaya Kemacetan}

Biaya kemacetan dibedakan pada dua jenis kendaraan pribadi yaitu sepeda motor dan kendaraan ringan. Biaya kemacetan sepeda motor pada kedua ruas jalan yang ditinjau disajikan pada Tabel 1.

Tabel 1. Biaya kemacetan sepeda motor pada kedua ruas jalan

\begin{tabular}{lcc}
\hline \multicolumn{1}{c}{ Ruas jalan/Jenis kendaraan } & \multicolumn{1}{c}{ Kecepatan (timur-barat) } & Kecepatan (barat-timur) \\
\hline Sepeda motor (Honda Revo 2012) & & \\
Dukuhwaluh & $38,63 \mathrm{~km} / \mathrm{jam}$ & $43,17 \mathrm{~km} / \mathrm{jam}$ \\
Kombas Suprapto & $40,48 \mathrm{~km} / \mathrm{jam}$ & $38,17 \mathrm{~km} / \mathrm{jam}$ \\
Waktu tempuh & & \\
Dukuhwaluh & $1.86 \mathrm{menit}$ & $1.67 \mathrm{menit}$ \\
Kombas Suprapto & $2.08 \mathrm{menit}$ & $2.2 \mathrm{menit}$ \\
$\begin{array}{l}\text { Penurunan kecepatan } \\
\text { Dukuhwaluh }\end{array}$ & $11,37 \mathrm{~km} / \mathrm{jam}$ & $6,83 \mathrm{~km} / \mathrm{jam}$ \\
Kombas Suprapto & $9,52 \mathrm{~km} / \mathrm{jam}$ & $11,83 \mathrm{~km} / \mathrm{jam}$ \\
Kelambatan & & \\
Dukuhwaluh & $0,35 \mathrm{~km}$ & $0,19 \mathrm{~km}$ \\
Kombas Suprapto & $0,33 \mathrm{~km}$ & $0,43 \mathrm{~km}$ \\
Kerugian kelambatan Rp/trip & & \\
Dukuhwaluh & $\mathrm{Rp} 119,5$ & $\mathrm{Rp} 65$, \\
Kombas Suprapto & $\mathrm{Rp} \mathrm{112,6}$ & $\mathrm{Rp} 146,8$ \\
\hline
\end{tabular}

Sedangkan biaya kemacetan pada kendaraan ringan disajikan pada Tabel 2.

Tabel 2. Biaya kemacetan kendaraan ringan pada kedua ruas jalan

\begin{tabular}{lcc}
\hline \multicolumn{1}{c}{ Ruas jalan/Jenis kendaraan } & Kecepatan (timur-barat) & Kecepatan (barat-timur) \\
\hline Kendaraan ringan (avanza 2012) & $38,5 \mathrm{~km} / \mathrm{jam}$ & $35 \mathrm{~km} / \mathrm{jam}$ \\
Dukuhwaluh & $39,5 \mathrm{~km} / \mathrm{jam}$ & $39 \mathrm{~km} / \mathrm{jam}$ \\
Kombas Suprapto & & 2.06 menit \\
Waktu tempuh & 1.87 menit & 2.15 menit \\
Dukuhwaluh & 2.13 menit & $15 \mathrm{~km} / \mathrm{jam}$ \\
Kombas Suprapto & & $11,5 \mathrm{~km} / \mathrm{jam}$ \\
Penurunan kecepatan & & \\
Dukuhwaluh & & \\
\hline
\end{tabular}

CIVeng Vol.1, No.1, Januari 2020 : 17 22 


\begin{tabular}{lll}
\hline Kombas Suprapto & $10,5 \mathrm{~km} / \mathrm{jam}$ & $11 \mathrm{~km} / \mathrm{jam}$ \\
Kelambatan & & \\
Dukuhwaluh & $0,36 \mathrm{~km}$ & $0,51 \mathrm{~km}$ \\
Kombas Suprapto & $0,37 \mathrm{~km}$ & $0,39 \mathrm{~km}$ \\
Kerugian kelambatan Rp/trip & & \\
Dukuhwaluh & $\mathrm{Rp} 656.28$ & $\mathrm{Rp} 929.73$ \\
Kombas Suprapto & Rp 674.51 & $\mathrm{Rp} 710.97$ \\
\hline
\end{tabular}

\subsection{Hubungan Kecepatan dengan Biaya Kemacetan}

Jika digambarkan kecepatan sesaat terhadap biaya kerugian yang dialami oleh sepeda motor dan mobil pribadi di J1 Raya Dukuhwaluh dan Jl. Komisaris Bambang Suprapto, sebagai berikut :

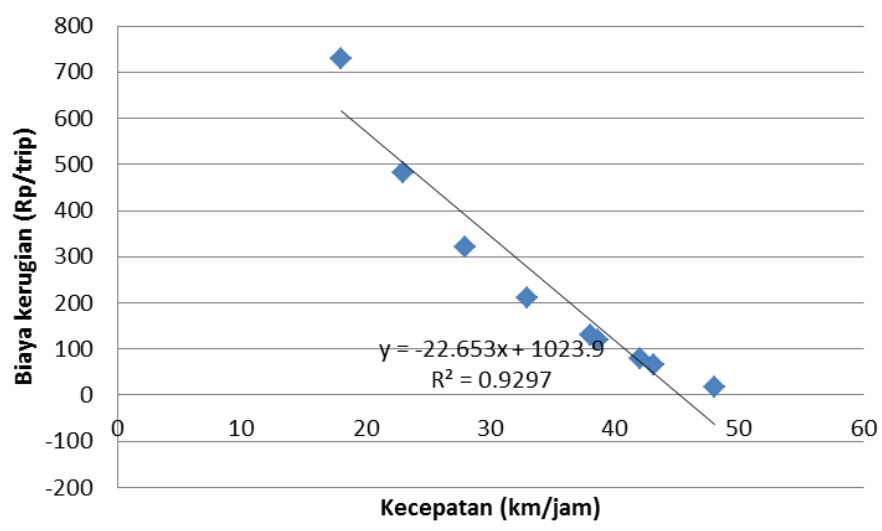

Gambar 5. Hubungan kecepatan sepeda motor terhadap biaya kemacetan J1 Raya Dukuhwaluh

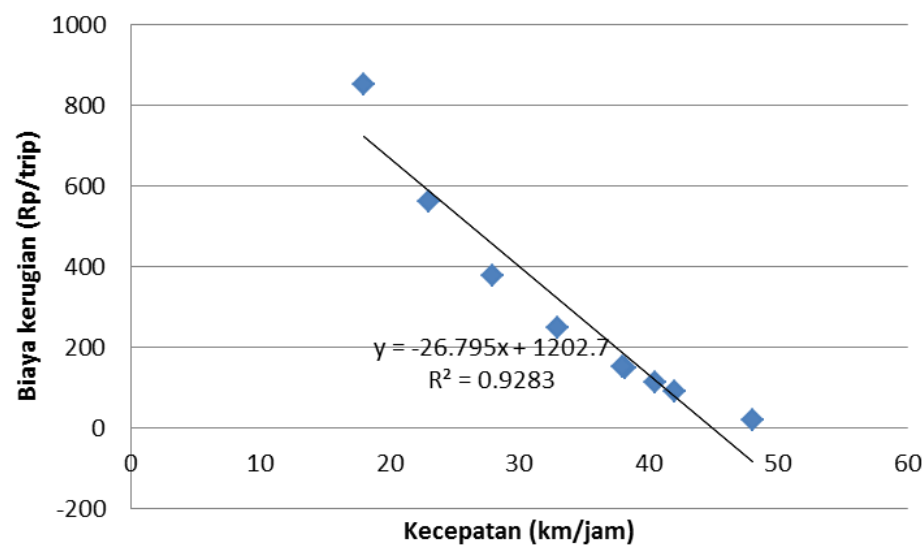

Gambar 6. Hubungan kecepatan sepeda motor terhadap biaya kerugian J1 Kombas Suprapto

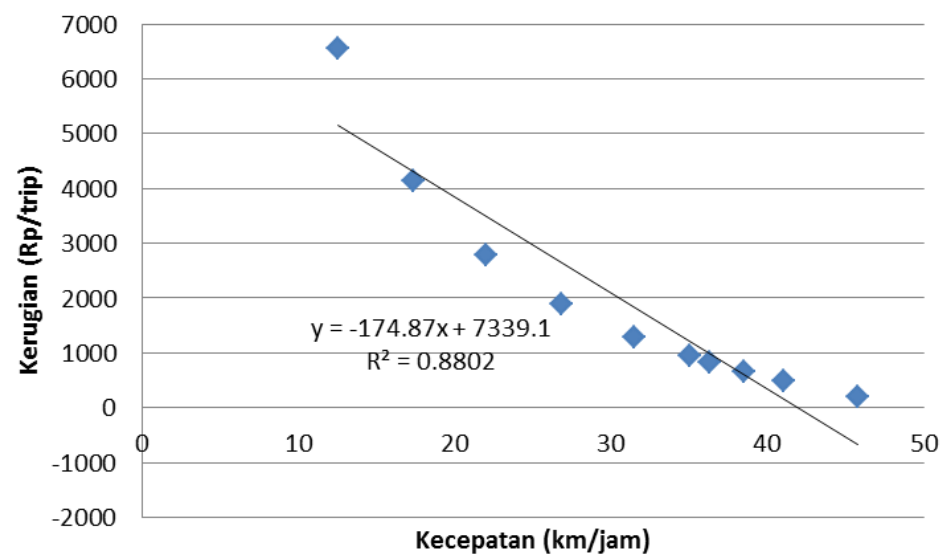

Gambar 7. Hubungan kecepatan kendaraan ringan terhadap biaya kerugian J1 Raya Dukuhwaluh 


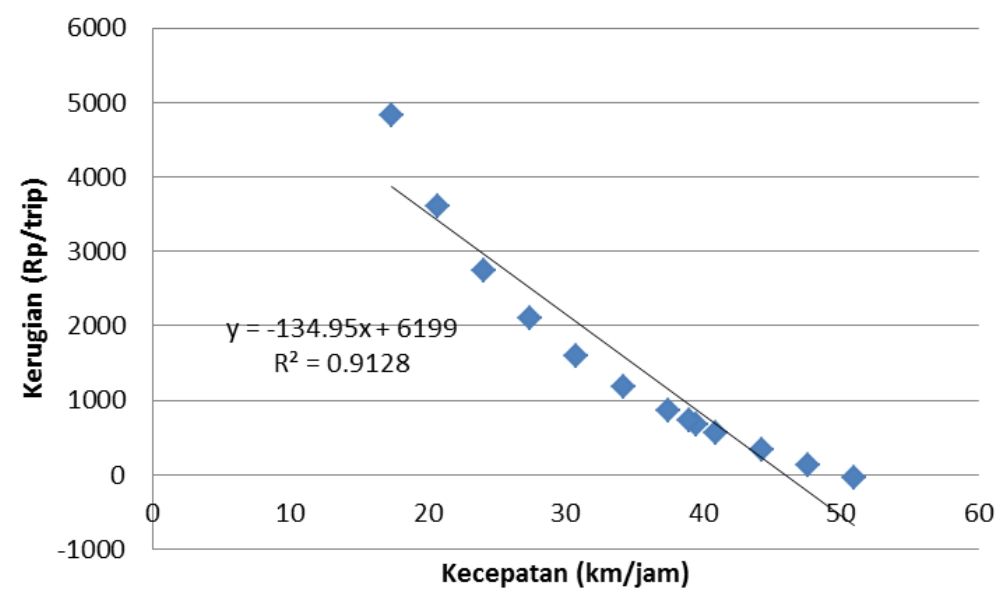

Gambar 8. Hubungan kecepatan sepeda motor terhadap biaya kerugian J1 Kombas Suprapto

Berdasarkan keempat gambar di atas, diketahui bahwa semakin lambat kecepatan kendaraan di jalan baik itu sepeda motor maupun kendaraan ringan maka akan menaikkan biaya kerugian akibat kemacetan di titik-titik atau spot kemacetan di kedua jalur jalan. Begitu juga sebaliknya jika kecepatan kendaraan di kedua jalur jalan tinggi atau sesuai dengan kecepatan operasional jalan tanpa ada titik-titik kemacetan maka biaya kerugian kemacetan rendah bahkan tidak ada.

\section{KESIMPULAN}

Berdasarkan hasil analisa yang telah dilakukan diperoleh kesimpulan bahwa perubahan kecepatan kendaraan baik sepeda motor maupun kendaraan ringan mempengaruhi biaya kerugian akibat kemacetan. Semakin rendah kecepatan maka akan mengakibatkan meningkatnya biaya kerugian akibat kemacetan. Biaya kerugian kemacetan dengan sepeda motor di Jl Raya Dukuhwaluh per trip sebesar Rp 119,50 arah timur barat, arah barat timur Rp 65,00, sedangkan Jl. Kombas Suprapto Rp 112,60 arah timur barat dan Rp 146,80- arah barat timur. Biaya kerugian kemacetan dengan mobil di J1 Raya Dukuhwaluh per trip sebesar Rp 656.28 arah timur barat dan arah barat timur Rp 929,73, sedangkan J1. Kombas Suprapto Rp 674,51,- arah timur barat dan Rp 710,97,- arah barat timur. Biaya kerugian akibat kemacetan pada kedua ruas jalan yaitu J1 Raya Dukuhwaluh dan J1 Kombas Suprapto dengan pemakaian kendaraan pribadi (sepeda motor dan mobil) lebih rendah dibandingkan naik angkot dengan tarif flat. Namun demikian diperlukan penelitian lanjutan terkait biaya kerugian akibat kemacetan pada trayek yang dilalui angkutan umum secara menyeluruh.

\section{DAFTAR PUSTAKA}

[1] BPS Kab Banyumas, Kabupaten Banyumas dalam Angka 2020, 2020.

[2] Juanita, S. Anjarwati, Analisis Bangkitan Pergerakan Perumahan di Purwokerto Berdasarkan Sosio Ekonomi, Purwokerto, 2013.

[3] Juanita, T. Pinandita, Kajian Kinerja Pelayanan Angkutan Umum dalam Kota di Purwokerto, in: Simp. Nas. Teknol. Terap. 2015, 2015. https://doi.org/ISSN : 2339-028X.

[4] T. Litman, Evaluating Transportation Land Use Impacts Considering the Impacts, Benefits and Costs of Different Land Use, 1 (2016) 9-16.

[5] B.S. Kerner, Introduction to modern traffic flow theory and control: The long road to three-phase traffic theory, 2009. https://doi.org/10.1007/978-3-642-02605-8.

[6] A. Tzedakis, Different Vehicle Speeds and Congestion Costs, J. Transp. Econ. Policy. 14 (1980) 81-103. 